\title{
Hepatic copper in primary biliary cirrhosis: biliary excretion and response to penicillamine treatment*
}

\author{
M P SALASPURO $\dagger$, P PIKKARAINEN, P SIPPONEN, E VUORI, AND \\ T A MIETTINEN \\ From the Second Department of Medicine, Division of Gastroenterology, University Central Hospital of Helsinki, \\ Helsinki, Finland
}

\begin{abstract}
SUMMARY Excessive hepatic copper accumulation occurs in long-lasting cholestatic liver disorders especially in primary biliary cirrhosis. As in Wilson's disease, penicillamine has recently been introduced for the treatment of primary biliary cirrhosis. In Wilson's disease there is decreased biliary excretion of copper. The present study shows that as compared with controls the biliary excretion of copper is not decreased in primary biliary cirrhosis; instead it may be increased in some patients. However, when compared with high hepatic copper concentration biliary copper excretion was low. In contrast with copper, biliary secretion of bile acids was decreased in eight of the 17 patients. Treatment with oral penicillamine $(600 \mathrm{mg} /$ day $)$ for one year resulted in a significant decrease of hepatic copper concentration, but had no consistent effect on the biliary excretion of copper or on the amount of histologically stainable orcein-positive copper-binding protein. The results suggest that excessive hepatic copper accumulation in primary biliary cirrhosis may not be primarily caused by a decreased biliary excretion, or that a new equilibrium is achieved in advanced primary biliary cirrhosis. D-penicillamine appears to improve significantly the biliary excretion of bile acids.
\end{abstract}

\begin{abstract}
Abnormal copper deposition in human liver has long been associated with Wilson's disease, 12 but it is also found in long-lasting cholestatic liver diseases; especially in primary biliary cirrhosis. 36 The biochemical events underlying these changes in copper metabolism are not understood and appear to be different in the two disease states. In Wilson's disease, the accumulated copper is initially diffusely distributed in the cytosol of the hepatocytes and later in the lysosomes. 78 Depending on the stage of the disease, this may be associated with a decreased hepatic uptake of radioactive copper, 9 with a decreased incorporation of labelled copper into the caeruloplasmin, ${ }^{10}{ }^{11}$ and with a decreased secretion of copper into the bile. 12 In primary biliary cirrhosis the accumulated copper is found mainly in the cytosol. 13 Newly arrived copper is preferentially handled and used by the liver for incorporation into caeruloplasmin without dilution in the expanded liver pool of the

* Presented in part in the Annual Meeting of the American Gastroenterological Association, Las Vegas 1978 (Abstract: Gastroenterology 1978; 74:1161).

†Address for correspondence and reprints: Dr M Salaspuro, Division of Gastroenterology, II Department of Medicine, University Central Hospital of Helsinki, 00290 Helsinki 29, Finland.

Received for publication 12 May 1981
\end{abstract}

metal. ${ }^{10}$ However, even in primary biliary cirrhosis, the incorporation of radiocopper into caeruloplasmin via the more rapid pathway appears to be impaired, ${ }^{11}$ though significantly less than in Wilson's disease. ${ }^{10}$

There is no information available about the biliary excretion of copper in patients with primary biliary cirrhosis. As this is the main site of copper elimination from the body, it was considered worthwhile to ascertain if changes in the biliary excretion of copper could account for the defect in copper metabolism in this disease. With this background the aims of the present study were (1) to quantify the biliary excretion of copper in primary biliary cirrhosis; (2) to study the effect of pencillamine treatment on this same parameter; (3) to relate biliary copper excretion to other hepatic functions, to biliary excretion of bile acids, and to hepatic copper content.

\section{Methods}

\section{PATIENTS}

The studies were carried out in 15 female and two male patients with primary biliary cirrhosis. Ages ranged from 22 to 70 years (mean 48 years). In each case the diagnosis was based on the typical clinical, biochemical, 
and histological findings already described 14 and the diagnostic criteria were similar to those reported by Sherlock and Scheuer. ${ }^{15}$ Histologically, three patients had florid duct lesion (stage 1), four had ductular proliferation (stage 2), seven patients exhibited scarring (stage 3), and three had cirrhosis (stage 4). ${ }^{16}$ The six controls (three male and three female) were healthy medical students aged from 24 to 27 years (mean 25 years). Informed consent was obtained both from patients and controls before the studies were carried out. After the initial biochemical studies the patients with primary biliary cirrhosis were randomly divided into two groups receiving either no drug treatment or penicillamine $(600 \mathrm{mg} /$ day $)$. The biliary secretion studies were repeated after one week and one year on the regimen.

\section{EXPERIMENTAL DESIGN}

After admission to the hospital all the patients with primary biliary cirrhosis and the controls were put on a standard low cholesterol diet containing $35 \%$ of energy as fat, $50 \%$ as carbohydrate, and $15 \%$ as protein. The daily energy content of the diet was $30-35 \mathrm{kcal} / \mathrm{kg}$ of body weight.

The basal biliary excretion rates of copper and bile acids were measured in 17 patients after seven days on the diet by the duodenal perfusion technique according to Grundy and Metzger. ${ }^{15}$ After an overnight fast a two-lumen radio-opaque tube (type $\mathrm{AN} 20, \mathrm{H}$ W Andersen Products Ltd, England) was positioned, under fluoroscopic control, so that the proximal outlet was situated in the second part of the duodenum. To make the gallbladder contract each patient received cholecystokinin (Pancreozymin, Boots Co. Ltd, England) 2 units per $\mathrm{kg}$ of body weight, up to a maximum dose of 100 units per patient, in $20 \mathrm{ml}$ of physiological saline intravenously.

The liquid formula used in the study was prepared from $20 \mathrm{ml}$ olive oil, $20 \mathrm{~g}$ fat-free milk powder, $4.5 \mathrm{~g}$ glycerol-1-mono-oleate (Fluka AG, Switzerland), and $200 \mathrm{ml}$ water by sonication. The energy content of the formula was $270 \mathrm{kcal}$. The formula contained $4 \mathrm{~g}$ polyethylene glycol 4000 (Fluka AG, Switzerland) as a nonabsorbable marker. The formula with markers was infused at a rate of $30 \mathrm{ml} / \mathrm{h}$ into the duodenum via the proximal outlet of the tube with an infusion pump (type 871 102, B Braun, Melsungen AG, West Germany). Samples of 5-10 $\mathrm{ml}$ were aspirated hourly through the outlets, which were located $15-20 \mathrm{~cm}$ more distally in the duodenum. Collections were made for up to six to eight hours. The samples obtained were placed in a water bath at $70^{\circ} \mathrm{C}$ for five minutes to destroy the lipase activity and then stored at $-20^{\circ} \mathrm{C}$ until analysed.

The biliary secretion rates of copper and bile acids (S) into the duodenum were calculated from the follow- ing equation using data of samples collected at six to eight hours of perfusion:

$$
\begin{aligned}
& \begin{array}{r}
\text { Biliary output } \\
\text { of } S / h
\end{array}=\frac{S_{a} \times P^{2} G_{p} \times V L_{p}}{P_{p}} \\
& \mathrm{~S}_{\mathrm{a}}=\text { concentration of } \mathrm{S} \text { in aspirate } \\
& \mathrm{PEG}_{\mathrm{p}}=\text { concentration of marker in perfusate } \\
& \mathrm{PEG}_{\mathrm{a}}=\text { concentration of marker in aspirate } \\
& \operatorname{VOL}_{p}=\text { hourly perfusion volume }
\end{aligned}
$$

Biliary secretion rates were re-evaluated after one week on penicillamine treatment $(600 \mathrm{mg} /$ day $)$ in 13 and after one year in seven of these patients.

\section{ANALYTICAL METHODS}

For the determination of hepatic copper, wedge liver biopsy samples (50-100 mg) obtained at laparoscopy were weighed into covered $10 \mathrm{ml}$ silica crucibles, dried overnight at $100^{\circ} \mathrm{C}$, and then dry-ashed at $450^{\circ} \mathrm{C}$. The ash was dissolved first with $0.5 \mathrm{ml} 6 \mathrm{M} \mathrm{HCL}$ (Suprapur, Merck) and then with $1 \mathrm{ml} 2 \mathrm{M} \mathrm{HCL}$ with gentle warming. The crucibles and covers were rinsed several times with small volumes of deionised water and finally diluted to $3 \mathrm{ml}$. The copper concentrations of the ash solutions were determined with the flame of flameless AAS-method (Perking-Elmer, model 300, with HGA 72). The details of the method have been described earlier. ${ }^{18}$ The effect of the sample size on the accuracy and precision of the method was tested with the Standard Reference Material No. 1577, Bovine Liver, produced by the National Bureau of Standards (NBS), Washington, D.C.

In order to overcome the exceptionally difficult matrix effect found in bile, the bile samples were also dry-ashed as described above. As a control, Seronorm standard serum (Seronorm, Batch No. 139, Nyegaard $\&$ Co, Oslo) produced by Medica Finland, was used.

Biliary bile acids were determined enzymatically according to Fausa. ${ }^{19}$ Polyethylene glycol was determined according to Hyden. 20

\section{HISTOLOGICAL METHODS}

To demonstrate copper-protein complexes 2122 the neutral formalin fixed paraffin embedded needle, or concotomy liver biopsies obtained in laparoscopy were stained by the method of Shikata et al.23 Before staining, the 5-8 $\mu$ tissue sections were oxidised in $0.3 \%$ potassium permanganate solution and decolourised in $1.5 \%$ oxalic acid. They were then stained for four hours in a solution of $1 \mathrm{~g}$ orcein (Merck), dissolved in $100 \mathrm{ml} 70 \%$ ethanol, adjusted to pH 2 with $\mathrm{HCL}$. Rubeanic acid stain and Mallory-Parker's haematoxylin reaction were used to demonstrate copper in the tissue sections. ${ }^{24}$ 
ST A TISTICS

Statistical significances between the groups were calculated according to the rank sum test ${ }^{25}$ and signed rank test $^{26}$ was used to compare the effect of treatment.

\section{Results}

\section{BILIARY EXCRETION OF COPPER}

In controls mean biliary excretion of copper $(49 \pm$ $44 \mu \mathrm{g} / \mathrm{h}$ ) was equal to earlier reports. ${ }^{12} 27$ In none of the patients with primary biliary cirrhosis was biliary copper excretion decreased (Fig. 1). In fact the mean excretion of copper was higher in the patients with primary biliary cirrhosis than in controls, but the difference was not statistically significant. Biliary copper excretion was remeasured in 13 of these patients after treatment with oral penicillamine $(600 \mathrm{mg} /$ day $)$ for one week (Fig. 1). Seven of these patients (Fig. 1) continued on penicillamine treatment for one year. As demonstrated in Fig. 1 penicillamine had no consistent effect on the biliary excretion of copper. Nor was it influenced by the histological stage of the liver disease.

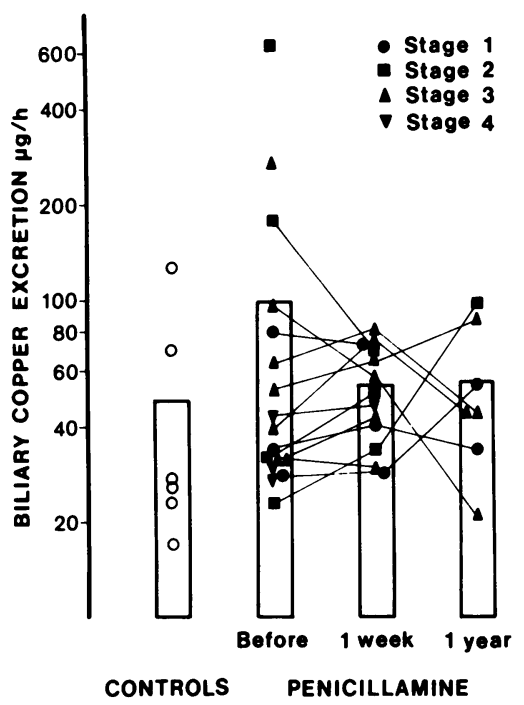

Fig. 1 Biliary copper excretion in patients with primary biliary cirrhosis and healthy controls. The effect of d-penicillamine (600 mg/day) treatment of one week or one year (individual patients connected with lines). The histological staging of the liver disease is indicated by symbols.

BILIARY EXCRETION OF BILE ACIDS

In contrast with copper, biliary excretion of bile acids was decreased in eight of 17 patients (Fig. 2). Treatment with penicillamine for one week had no effect on biliary

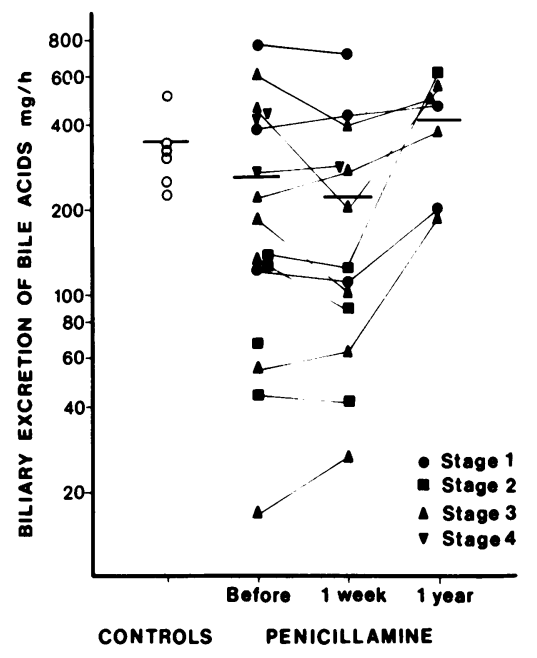

Fig. 2 Biliary excretion of bile acids in patients with primary biliary cirrhosis. The effect of d-penicillamine (600 mg/day) treatment of one week or one year (individual patients connected with lines). The histological staging of the liver disease is indicated by symbols.

secretion rate of bile acids. However, after one year of penicillamine, biliary excretion of bile acids was significantly $(\mathrm{P}<0.02)$ improved compared with pre-treatment values (Fig. 2). This cannot be explained by daily variation in biliary excretion, as the excretions in the first two measurements at one week's interval were almost identical. Biliary excretion of bile acids could not be related to the histological stage of the liver disease and there was no correlation between the biliary excretion rate of copper and that of bile acids.

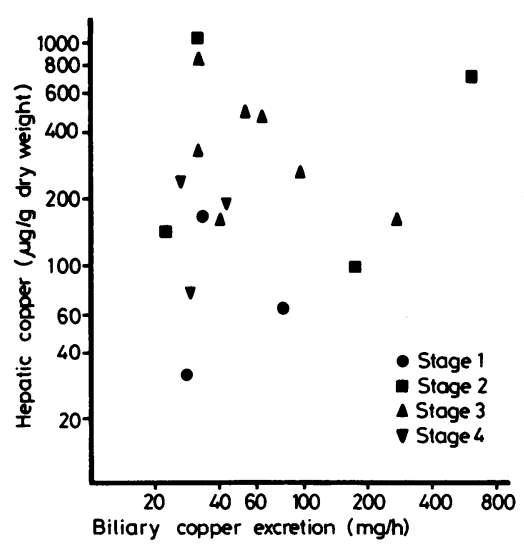

Fig. 3 Hepatic copper content as correlated with biliary excretion of copper. 


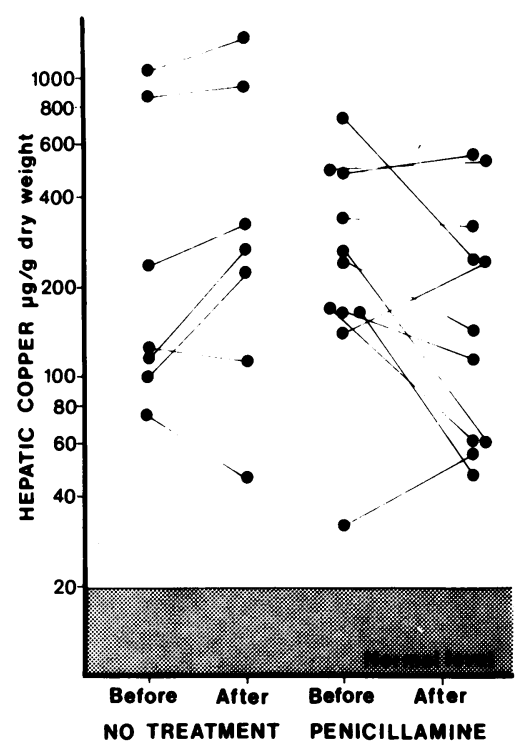

Fig. 4 The effect of d-pencillamine treatment ( $600 \mathrm{mg} /$ day) of one year on the hepatic copper concentration. The material includes one patient not participating in the excretion studies.

\section{HEPATIC COPPER}

There was no correlation between the biliary excretion of copper and hepatic copper content (Fig. 3). Although penicillamine treatment had no effect on the biliary excretion of copper, it did decrease hepatic copper in most of the patients (Fig. 4). On the other hand, in patients who were given no active drug treatment hepatic copper tended to increase during the one year period of follow-up. However, the decrease in the amount of chemically measurable copper in treated patients was not associated with a similar decrease in the amount of histologically stainable copper or copperbinding protein. This was confirmed independently and blindly by two pathologists. Their interpretation as to orcein- and/or rubeanic acid positivity before and after penicillamine is shown in the Table.

Table Hepatic copper-protein complexes before and after penicillamine

\begin{tabular}{ccc}
\hline Patient & Before penicillamine & $\begin{array}{c}\text { After one year's treatment } \\
(600 \mathrm{mg} / \text { day })\end{array}$ \\
\hline 1 & +++ & ++ \\
2 & + & + \\
3 & ++ & +++ \\
4 & ++ & + \\
5 & + & +++ \\
6 & ++ & ++ \\
8 & ++ & ++ \\
9 & ++ & \\
\hline
\end{tabular}

+ orcein or rubeanic positive material in some single hepatocytes. ++ positive granules focally in periportal liver cells. ...+ positive material diffusely in periportal and also in central areas of liver lobules.

\section{Discussion}

Histologically, four stages of primary biliary cirrhosis have been defined.16 28 The earliest-florid duct lesion -is characterised by inflamed swollen portal tracts with the affection of septal and interlobular bile ducts. In more advanced stages, there is ductular proliferation, scarring, and, finally, cirrhosis. Hepatic copper accumulations are infrequently seen in the early stages of primary biliary cirrhosis. ${ }^{5} 1621$ Orcein-positive copper complexes are typically seen in the late stages of the disorder, and in cases which are biochemically characterised by high serum levels of alkaline phosphatase, gamma-glutamyl-transpeptidase, leusine aminopeptidase, bile acids and cholesterol, and by greatly decreased bromsulphthalein transport maximum. ${ }^{14}$ On this basis the excessive hepatic copper accumulation in primary biliary cirrhosis must be a secondary phenomenon, although copper has been shown to be a hepatotoxin in experimental animals, ${ }^{29}$ in acute poisoning in man, ${ }^{30}$ and in patients with Wilson's disease. ${ }^{31}$ Either the damage to the bile ducts and ductules interferes with the normal biliary secretion of copper or hepatocytes affected by cholestasis for some reason accumulate abnormal amounts of copper.

In contrast with the findings in the present study with patients with primary biliary cirrhosis biliary excretion of copper is defective in Wilson's disease. ${ }^{12}$ However, hepatic copper concentrations are indistinguishable in both of these diseases. ${ }^{5}$ In late Wilson's disease the low biliary concentration of copper is associated with a very high concentration of copper in hepatic lysosomal fractions. ${ }^{8}$ On the basis of this finding it has been suggested that a defective excretion of copper from hepatic lysosomes to bile underlies the accumulation of excess copper in Wilson's disease.

In the early stages of both primary biliary cirrhosis and Wilson's disease most of the excess liver copper is found in the cytosol. ${ }^{72}$ Since, as shown in this study, the biliary excretion of copper is not decreased in even the early stages of primary biliary cirrhosis the basic reason for the copper accumulation could be the decreased incorporation of radiocopper into ceruloplasmin via a so-called more rapid pathway 11 or an increased hepatic uptake of copper. It is also possible that, in the early phase of the disease, the biliary copper excretion is defective. However, in the later stages, a new equilibrium could have been reached where biliary excretion is at normal range, but still low when compared with the degree of hepatic copper accumulation. This possibility cannot be ruled out, as all of our patients had an increased hepatic copper content.

In primary biliary cirrhosis the excess hepatic copper appears to be bound to protein-forming orceinpositive intracellular aggregates. ${ }^{21}$ These complexes contain high amounts of sulphur residues capable of 
copper complexing. 2132 The high copper and sulphur content of these complexes has also been demonstrated by $x$-ray microanalysis, which suggests that the molecular ratio of sulphur to copper in the accumulations is $2: 1.33$ In the advanced stage of the disease these copper-protein complexes are electromicroscopically stored in the lysosomes. ${ }^{34}$

As in Wilson's disease d-penicillamine has recently been introduced for the treatment of primary biliary cirrhosis. In controlled studies the drug has been shown to decrease hepatic copper concentration, serum transaminase levels, and the degree of histological cholestasis. ${ }^{35} 36$ Also in this study penicillamine treatment for one year decreased the content of chemically measurable copper in the liver, but it had no effect on the orcein-positive copper-protein complexes. The findings suggest that penicillamine primarily removes copper from the hepatic cytosol, but not from the lysosomal aggregates. The decrease in the cytosolic copper was associated with the improvement of the biliary secretion of bile acids, which indicates an improved hepatic function during d-penicillamine treatment.

The excellent technical assistance of Mrs Leena Kaipiainen and Miss Tuula Moisio is gratefully acknowledged.

\section{References}

'Scheinberg IH, Sternlieb I. Wilson's disease. Ann Rev Med $1965 ; 16: 119-34$.

2Walshe JM. Wilson's disease. The presenting symptoms. Arch Dis Child 1962;37:253-6.

${ }^{3}$ Hunt AH, Parr RM, Taylor DM, Trott NG. Relation between cirrhosis and trace metal content of liver: with special reference to primary biliary cirrhosis and copper. Br Med J 1963; 2:1489-501.

${ }^{4}$ Leeson PM, Fourman P. A disorder of copper metabolism treated with penicillamine in a patient with primary biliary cirrhosis and renal tubular acidosis. Am J Med $1967 ;$ 43:620-35.

5Fleming CR, Dickson ER, Baggenstoss AH, McCall JT. Copper and primary biliary cirrhosis. Gastroenterology $1974 ; 67: 1182-7$.

${ }^{6}$ Ritland S, Steinnes E, Skrede S. Hepatic copper content, urinary copper excretion, and serum ceruloplasmin in liver disease. Scand J Gastroenterol 1977; 12:81-88.

${ }^{7}$ Goldfischer S, Sternlieb I. Changes in the distribution of hepatic copper in relation to the progression of Wilson's disease (hepatolenticular degeneration). Am J Path 1968; 53:883-901.

${ }^{8}$ Sternlieb I, van den Hamer CJA, Morell AG, Alpert S, Gregoriadis G, Scheinberg IH. Lysosomal defect of hepatic copper excretion in Wilson's disease (hepatolenticular degeneration). Gastroenterology 1973; 64:99105.

9Smallwood RA, McIlveen B, Rosenoer VM, Sherlock S. Copper kinetics in liver disease. Gut 1971; 12:139-44.

${ }_{10}$ Gibbs K, Walshe JM. Studies with radioactive copper $\left({ }^{64} \mathrm{Cu}\right.$ and $\left.{ }^{67} \mathrm{Cu}\right)$; The incorporation of radioactive copper into caeruloplasmin in Wilson's disease and primary biliary cirrhosis. Clin Sci 1971; $41: 189-202$. .

11 Vierling JM, Shrager MD, Warren MA, Rumble F, Aamodt BAR, Berman MD, Jones EA. Incorporation of radiocopper into ceruloplasmin in normal subjects and in patients with primary biliary cirrhosis and Wilson's disease. Gastroenterology 1978; 74:652-60.

${ }^{12}$ Frommer DJ. Defective biliary excretion of copper in Wilson's disease. Gut 1974; 15:125-9.

${ }^{13}$ Owen CA, Dickson ER, Goldstein NP, Baggenstoss AH, McCall JT. Hepatic subcellular distribution of copper in primary biliary cirrhosis. Comparison with other hepatocupric states and review of the literature. Mayo Clin Proc 1977; 52:73-80.

${ }^{14}$ Salaspuro MP, Sipponen P, Ikkala E, Kolho L, Makkonen HM, Miettinen TA, Räsänen JA, Siurala M. Clinical correlations and significance of orcein positivity in chronic active hepatitis and primary biliary cirrhosis. Ann Clin Res 1976;8:206-15.

${ }^{15}$ Sherlock S, Scheuer PJ. The presentation and diagnosis of 100 patients with primary biliary cirrhosis. $N$ Engl J Med 1973; 289:674-8.

16Sipponen P, Salaspuro MP, Makkonen H. Histological characteristics of chronic hepatides and primary biliary cirrhosis with special reference to orcein positive hepatocellular accumulations. Ann Clin Res 1976; 8:200-5.

${ }^{17}$ Grundy SM, Metzger AL. A physiological method for estimation of hepatic secretion of biliary lipids in man. Gastroenterology 1972; 62:1200-6.

18 Vuori E, Huunan-Seppälä A, Kilpiö JO. Biologically. active metals in human tissues. I. The effect of age and sex on the concentration of copper in aorta, heart, kidney, liver, lung, pancreas and skeletal muscle. Scand $J$ Work Environ Health 1978; 4:167-75.

${ }^{19}$ Fausa $O$. Quantitative determination of serum bile acids using a purified 3-beta-hydroxysteroid dehydrogenase. Scand J Gastroenterol 1975; 10:747-52.

${ }^{20}$ Hyden S. A turbidometric method for the determination of higher polyethylene glycols in biological materials. Kungl Lantbrukshögskolans Annaler 1955; 22:139-45.

${ }^{21}$ Salaspuro M, Sipponen P. Demonstration of an intracellular copper-binding protein by orcein staining in longstanding cholestatic liver diseases. Gut 1976; 17:787-90.

22 Salaspuro MP, Sipponen P, Makkonen H. The occurrence of orcein-positive hepatocellular material in various liver diseases. Scand J Gastroenterol 1976; 11:677-81.

${ }^{23}$ Shikata T, Uzawa T, Yoshiwara N, Akatsuka T, Yamazaki S. Staining methods of Australia antigen in paraffin section. Detection of cytoplasmic inclusion bodies. Jap J Exp Med 1974; 44:25-36.

24Pearse AEG. Histochemistry: theoretical and applied. Vol. 2. London: Churchill, 1972: 1411-19.

${ }^{25}$ West ED. The signed rank (Wilcoxon) test. Lancet 1969 ; $1: 526$.

${ }^{26}$ Wilcoxon F. Individual comparisons by ranking methods. Biometrics Bull 1945; 1:80.

${ }^{27}$ Henegouwen van Berge GP, Tangedahl TN, Hofmann AF, Northfield TC, LaRusso NF, McCall JT. Biliary secretion of copper in healthy man. Quantitation by an intestinal perfusion technique. Gastroenterology 1977; 72:1228-31. 
28Scheuer PJ. Primary biliary cirrhosis. Proc Roy Soc Med 1967; 60:1257-60.

${ }^{29}$ Todd JR, Gracey JF, Thompson RH. Studies of chronic copper poisoning. I. Toxicity of copper sulfate and copper acetate in sheep. Br Vet $J 1962$; 118:482-91.

${ }^{30}$ Chuttani HK, Gupta PS, Gulati S, Gupta DN. Acute copper sulfate poisoning. Am J Med 1965; 39:849-54.

31Sternlieb I, Scheinberg IH. Wilson's disease. In: Wright R, Alberti KGMM, Karran S, Millward-Sadler GH, eds. Liver and biliary disease. Pathophysiology, diagnosis, management. London: Saunders 1979; 774-87.

32Sipponen $\mathbf{P}$. Orcein positive hepatocellular material in longstanding biliary diseases. I. Histochemical characteristics. Scand J Gastroenterol 1976; 11 :545-52.
33Sipponen P, Hjelt L, Törnkvist T, Salaspuro M. X-ray microanalysis of copper accumulation in liver in secondary biliary cirrhosis. Arch Pathol Lab Med 1976; 100:664-66.

${ }^{34}$ Sipponen $\mathbf{P}$. Orcein positive hepatocellular material in longstanding biliary diseases. II. Ultrastructural studies. Scand J Gastroenterol 1976; 11 :553-7.

${ }^{35}$ Deering TB, Dickson ER, Fleming CR, Geall MG, McCall JT, Baggenstoss AH. Effect of d-penicillamine on copper retention in patients with primary biliary cirrhosis. Gastroenterology 1977; $72: 1208-12$.

36Jain S, Scheuer PJ, Samourian S, McGee JOD, Sherlock S. A controlled trial of D-penicillamine therapy in primary biliary cirrhosis. Lancet 1977; 1:831-34. 